\title{
The System of Management of Regional Development in Poland: New Legal and Administrative Proposals
}

UDK: $332.14(438)(045)$

\author{
Marcin Szewczak \\ John Paul II Catholic University of Lublin \\ Faculty of Law, Canon Law and Administration \\ szewczak@kul.pl
}

\section{ABSTRACT}

This paper describes the new proposal being advanced regarding the legal and administrative aspects of regional development in Poland, presenting a smallscale survey of part of the legal system as it pertains to regional development. It outlines the new legal proposal for implementation with regard to the preparation of solutions necessary for the next programming period (20142020). The results of the analysis suggest that the solutions proposed may be effective and may contribute to improving the system.

Key words: regional development, management of regional development, regional territorial forum, cohesion policy, EU regional policy

JEL:

\section{Introduction}

The most important entities charged with implementing regional development policy in Poland are the state (central government) and local government at the województwa (provincial) level; these are the entities mainly responsible for the level of development of the regions. On behalf of central government, the entity responsible for the particular shape of national regional development policy is the Ministry of Regional Development. Under the relevant act of 6 December 2006, the minister coordinates implementation of the national development strategy. Despite the fact that the act has now been in force for five years, there are numerous aspects that still need to be regulated; a number have been proposed for implementation as a step towards the preparation of solutions necessary for the next programming period, which is 2014-2020. This paper provides a preliminary analysis of the activities mentioned above. Of course, it is too early to come to firm

Szewczak, M. (2012). The System of Management of Regional Development in Poland: New Legal and Administrative Proposals. Uprava/Administration X(2), 115-121. 115 
conclusions regarding the effectiveness of these measures, but it is a good time for discussion and reflection.

\section{Legal foundations of regional development in Poland}

Research into the concept of the region has been conducted in various fields of science, including economics, political science, law, sociology and spatial development. The term »region « is used in both everyday language and by specialists (Kokocińska, 2009, p.13). Most European countries have regions whose level of economic development (and consequently standard of living) are lower than that of the leading European Union Member States. As far as regional policy is concerned, it can be noted that it is characterised by the specific directions fostered by the political and structural concepts of the EU - therefore, regional policy activities focus on a single region, area or Member State (Kukliński, 2003, pp. 5-14). Each region is free to broaden or limit the support and intervention of the Funds, and to change their character. Individual regional development instruments should complement each other (Głąbicka \& Grewiński, 2004, p. 33).

The key document relating to the implementation of EU cohesion policy in Poland between 2007 and 2013 is the Act of 6 December 2006, laying down the principles of conduct of development policy. According to this act, state development policy is determined by development strategies and subsequently implemented by specific operational programmes and implementation plans. The 2007-2015 National Development Strategy (NDS) is the principal long-term strategic document defining the goals and priorities of Poland's social and economic development, and the conditions aimed at securing the development objectives. The strategy defines objectives and identifies those areas recognised as being of greatest importance in achieving these aims; the activities of the state will be concentrated on those areas. The major role of the NDS is to coordinate institutional and regulatory reforms with the activities financed by EU Funds so that, through synergy, these two areas produce the best possible pro-development effects. The main goal of the NDS is to increase the level and quality of life of Polish citizens, residents and families, which means an increase in household income and easier access to education and training, which leads to an improvement in society's level of education and citizens' skills and qualifications, as well as an increase in employment and productivity, resulting in lower rates of unemployment, a rise in the level of professional activity and improvements to health (NDS, p. 29).

The National Strategic Reference Framework 2007-2013 (NSRF) (NSRF, p. 22 ) is a document designed to aid implementation of EU cohesion policy in Poland. NSRFs have to be drawn up in accordance with Council Regulation (EC) No 1083/2006 of 11 July 2006. The preparation of NSRFs and their approval by the European Commission are necessary prerequisites for Commission 
approval of operational programmes and, as a result, for the allocation of resources from structural funds. The NSRF specifies the priorities, areas of activity and methods of implementation of EU Funds in Poland by determining, among other things, the number of operational programmes and the level of funds allocated for their implementation. Since the Act laying down the principles of conduct of development policy has been in force without major changes for several years, it has become necessary to introduce a number of amendments. The forthcoming new programming period in the European Union has, to some extent, accelerated the process.

\section{Improvements to the regional development management system - an analysis of amendments to the law}

Individual solutions introduced by amendments to the law have been the result of decisions taken by the Council of Ministers and, in particular, the adoption, on 13 July 2010, of the National Regional Development Strategy 2010-2020 - Regions, Cities, Rural Areas (NRDS). The NRDS is the first of nine so-called »integrated strategies" and it outlines the directions to be taken by systemic changes and institutional transformations aimed at increasing the efficiency and effectiveness of regional policy and other public policies with an impact on development processes in territorial systems. In adopting the NRDS, the Council of Ministers brought forward numerous innovative solutions aimed at streamlining the management and conduct of regional policy and concerning its programming system, implementation and monitoring. Some of the amendments aim at improving or eliminating those acts that have not been implemented for reasons relating to procedure or content. The amendments proposed in the draft pertain to regulation of the institutional system and systematisation of the strategic activities undertaken at both the central and regional levels by entities involved in the management of national development processes, including those units involved in the implementation of structural funds and the Cohesion Fund (Project, p. 1).

A new development management system assumes the coexistence of various kinds of strategic document. The basic documents include a medium- and long-term national development strategy, as well as other strategies that implement and relate to the areas and fields indicated in the medium-term strategy. The introduction of an additional document category, that of the »long-term policy" (Article 1 item 2 of the draft) is designed to fill the gap that has appeared in the strategic document system between strategies for developing areas indicated in the medium-term national development strategy and the programmes that implement particular solutions. Chapter 2a, newly introduced into the act in Article 1 item 7 of the draft, defines longterm policies as those documents that facilitate the coordination of activities undertaken and implemented by a minister within their area of responsibility; they should refer to a specific sector or an area of social and economic life indicated in the development strategies. Therefore, long-term policies do 
not introduce additional development goals but, instead, specify the way in which the goals determined in the strategies should be implemented. At the same time, they are not implementation documents in the way that programmes are: the policies are designed to act as tools for ministers to help them coordinate activities within the scope of their remit. To ensure the cohesion of strategic programming, the long-term policies will, similarly to strategies and programmes, be evaluated as far as their compatibility with the development goals indicated in the medium-term national development strategy are concerned (Project, p. 1).

The most important instrument determining the common objectives identified for a particular territory and coordinating pro-development activities undertaken by central and local government is the territorial contract referred to in the NRDS. The territorial contract has been introduced into the act in Article 1 items $3 a$ and 10 of the draft. It changes the method used to determine national and regional development activities that has been in place so far and had been based on a "provincial contract«. The territorial contract is not an agreement that transfers financial resources - it only indicates commonly identified development goals, the methods employed to achieve them, the sources of financing (state funds, EU funds and local government funds, including funds from provinces, powiaty [counties/districts] and gminy [towns/rural communities]), and the conditions necessary for realising development activities in the region (e.g. activities at the national level). Such a territorial contract should include activities realised at the national level (by particular departments indicated in the territorial contract) and at the regional level (activities conducted by various units of local government, namely the province, county/district and town/rural community). At the national level, the Council of Ministers is represented by the minister in charge of regional development, who signs the territorial contract on behalf of the Council of Ministers and after consultation with respective ministers. Local government (i.e. the government of the province, county/district and town/ rural community) is represented by an assembly, or by assemblies of provinces in cases where the territorial contract extends across the area of more than one province. This solution is aimed at facilitating a proper assessment of territorial potentials and identifying tasks for the implementation of regional policy objectives in the form of a contract, where the parties involved include different public entities (i.e. they do not include central and provincial government alone, as was in the case with the "provincial contract«).

Another solution aimed at facilitating coordination and increasing the effectiveness of implementation of development activities is the Integrated Regional Framework Programme (IRFP), introduced into the act in Article 1 items $3 b$ and 11 of the draft. The IRFP describes the method to be employed to coordinate and integrate activities conducted by various public entities for a particular region within the framework of different instruments at the regional level. Therefore, according to the law, the IRFP is not a programme 
as such (it is neither an operational programme, nor a development programme), but is designed to define areas in which intervention is needed and to describe the expected results and the tools necessary to conduct this intervention, the financial resources and the sources of financing of activities, regulations concerning the coordination of activities within the framework of particular instruments (programmes), and the entities responsible for the implementation of individual tasks (e.g. different units of local government). While the territorial contract describes activities at both the national and regional levels that have an impact on the territory defined in the contract, the IRFP refers to activities undertaken at the regional level (Project, p. 2).

As a result of the introduction of the territorial contract and the Integrated Regional Framework Programme, a number of amendments to some of the regulations of the Provincial Government Act have been proposed. Since both the territorial contract and the IRFP are designed to support implementation of the pro-development activities defined in the Provincial Development Strategy, amendments to Article 11 paragraph 3 of the Provincial Government Act (Article 2 item 1 b) have been suggested in which both instruments are indicated as implementing the provincial development strategy.

At the same time, the competences of a provincial assembly defined in Article 18 of the Provincial Government Act have been broadened to include adoption of the Integrated Regional Framework Programme (Article 2 item 3 of the draft). The tasks of the provincial assembly laid down in Article 41 paragraph 2 of the Provincial Government Act have also been expanded to include preparation of the Integrated Regional Framework Programme (Article 2 item 4 of the draft).

As a result of the introduction of the territorial contract, an amendment to Article 42 paragraph 1 of the Local Government Revenues Act has been proposed (Article 3 of the draft). This amendment will allow local government units to obtain funds from the central government budget to subsidise priority enterprises included in this contract (Project, p. 3).

The results of research and analysis, as well as the conclusions drawn from the implementation of European Union Funds, indicate many weaknesses resulting from the sector-by-sector approach taken to the programming and realisation of support, a lack of cooperation between sectors and levels, and insufficient access to specific information and data for the strategic management of development. This leads to problems in defining the development goals, particularly in the regional system, a lack of cohesion in the way the policies are implemented, and insufficient coordination of the programming and implementation levels. If development policy is to be conducted efficiently and effectively, the strategic aspect of development policy must be strengthened, among other things, by the establishment of an institutionalised space for the exchange of information, knowledge and experience. This space would be the site of an ongoing strategic discussion 
aimed at determining the best possible framework for public intervention within the context of EU cohesion policy, regional policy and the territorially directed sectoral policies that make up development policy, as well as the most effective ways of using their influence to change internal and external conditions. In order to do that, a new Chapter 5 a has been added to Article 1 item 15 of the draft. This chapter (»Institutional Service of Development Policy" in the act laying down the principles of development policy) describes how consultative and advisory bodies are established within the support system of strategic thinking, including a State Territorial Forum (STF) at the national level (Ministry of Regional Development) and its counterparts at the regional level (at provincial assemblies), called Regional Territorial Forums (RTFs). The STF is a forum that facilitates the exchange of experience and good practice between all parties involved in work on development at the national level; the main goal of the RTFs is to establish common ground for cooperation and for the coordination of processes relating to the implementation of provincial development policy, with the participation of those units of provincial government responsible for that policy and the major entities involved in its implementation. The STF will stimulate and shape strategic thinking on development at the national level, while the RTFs will achieve this at the regional level. The purpose of the STF and RTFs is to increase the effectiveness of the process of spatial planning and the implementation of public tasks. This form of intraregional cooperation serves to determine common goals and to reconcile disparate sectoral and territorial interests. A further important role of these bodies is to increase the real possibility for the coordination of development processes at both the national and regional levels in, among other things, the process of the implementation of the territorial contract (Project, p. 3).

\section{Conclusion}

The new solutions described above and aimed atstreamlining the development management system in Poland are solutions currently undergoing both public and interdepartmental consultation. The indications are that the solutions proposed may be effective and may contribute to improving the system. Nevertheless, it is likely that the effects of these changes will not be felt for a number of years.

Marcin Szewczak - Biograpy 


\section{References}

- Głąbicka K. \& Grewiński, M. (2004). Europejska polityka... [European Policy...]. Warsaw.

- Kokocińska K. (2009). Polityka regionalna w Polsce i w Unii Europejskiej [Regional Policy in Poland and the European Union]. Poznań.

- Kukliński A. (2003). O nowym modelu polityki regionalnej - artykuł dyskusyjny [On the New Model of Regional Policy - A Discussion Article]. Studia Regionalne i Lokalne [Regional and Local Studies] 4(14)/2003, 5-14.

- NDS. National Development Strategy 2007-2013. Warsaw: Ministry of Regional Development.

- NSRF (2007). National Strategic Reference Framework 2007-2013. Warszawa: Ministry of Regional Development.

- Project (2011). Justification of the Project of the Amendment to the Act Laying Down the Principles of Conduct of Development Policy. Warsaw: Ministry of Regional Development. 